\title{
Mapping the Spatial Distribution of Rabies in Kaduna State, Nigeria (1999-2009) Using Geographic Information Sytems Technology
}

\author{
Asabe Adamu Dzikwi \\ Department of Veterinary Public Health and Preventive Medicine \\ Ahmadu Bello, University, Zaria, Nigeria \\ Idowu Innocent Abbas (Corresponding author) \\ Department of Geography, Ahmadu Bello University, Zaria, Nigeria \\ E-mail: innoabbas@yahoo.com
}

$\begin{array}{ll}\text { Received: December 14, } 2011 & \text { Accepted: February 2, 2012 Published: March 1, } 2012 \\ \text { doi:10.5539/enrr.v2n1p24 } & \text { URL: http://dx.doi.org/10.5539/enrr.v2n1p24 }\end{array}$

\begin{abstract}
Geographic Information System (GIS) has been employed as a viable tool in various epidemiological studies. Rabies is endemic in Nigeria among the reservoir host; the domestic dog Canis familiaris and human exposures are very common. Though rabies is almost $100 \%$ fatal, it is also $100 \%$ preventable and the most cost-effective means of preventing the disease in man is to control the disease in dogs. Kaduna State is one of the states with high records of rabies in Nigeria. This study therefore was carried out to determine the spatial distribution of rabies in Kaduna State, Nigeria from records obtained from the Kaduna State Ministry of Agriculture, track the spread, assess the distribution of vaccines, and plan a control strategy for rabies in the state. Data obtained was inputted into GIS environment using Arc GIS 9.2 software and a digital map of Kaduna State that was geo-referenced. The 11 year record of rabies in Kaduna State indicates cases of the disease reported annually except in 2001, 2003 and 2005. The modal case of 2 was reported in 2000, 2004 and 2006. A total of 32 cases were reported, and 43.75\% of the cases occurred in 2007. The cases were concentrated in the southern and eastern regions of the state. Lere local government area (LGA) was a hot-spot for the disease in 2007 and 2009. In 2007, Kajuru was also a hot spot. Kauru LGA sandwiched by hotspots recorded no outbreak throughout the period. In all, there were 37 human exposures following dog bites, and 7 (18.9\%) human mortalities. At least 420,000 vaccines were required but only 14,232 were distributed during the period. There was no vaccine distribution in the state for 5 years (2001-2003 and 2008-2009). Vaccine distribution did not have a logical pattern.
\end{abstract}

Keywords: GIS, Incidence, Kaduna State, Mapping Rabies, Nigeria, Vaccine

\section{Introduction}

Rabies is an infectious disease characterized by acute encephalitis. It is a highly fatal viral zoonosis. The infection is characterized by hydrophobia, disturbance of the central nervous system which results in paralysis and death. The disease affects all warm-blooded animals including man (Radostits et al., 1995). This infection has a case fatality rate of almost $100 \%$, accounting for about 55,000 human deaths annually with most cases occurring in developing countries of Asia and Africa (WHO, 1994). Rabies also has great agricultural and economic significance (Rupprecht et al., 2006) and is maintained either in the sylvatic or domestic cycles by various animal reservoirs. The main reservoirs in the Americas are in bat species and terrestrial carnivores including foxes, raccoons and coyotes. In the developing nations particularly in Asia and Africa, the domestic dog is the main reservoir of the infection. Although the disease is highly fatal, it is $100 \%$ preventable by the use of safe and effective vaccines. Rabies has been successfully controlled in countries where it was once endemic in the domestic dog by careful planning and implementation of vaccination programmes (Organizacion Panamericana de la Salud, 1983). The most cost-effective means of controlling this disease is by mass vaccination of the reservoirs because post-exposure prophylaxis in humans is much more costly (Kaare, 2007). Successful control programmes require adequate planning which can be carefully done if the spatial and temporal distribution of the disease can be 
mapped to guide distribution of rabies vaccines for animals as well as stockpiling of human vaccines in cases of exposures to the disease.

Rabies was first reported in Nigeria in 1912 (Boulger \& Hardy, 1960). Though there is a steady increase in the number of human cases of rabies in Nigeria, accurate and reliable information is lacking just as is the case in most countries of Africa (Taiwo et al., 1998). The infection is endemic among the canine population and dogs remain the primary reservoirs of the virus in the developing world, with human exposure being common. Control measures in dogs have been ineffective (Perry, 1993) possibly because of poor planning and execution of control programmes among other things. About $99 \%$ of persons exposed to rabies have been bitten by a domestic dog (WHO, 2005). The estimated dog population in Nigeria as at early 1990s was between 3-4 million (Oboegbulem, 1994). It is expected to be well above this figure now, and most dogs are kept without any history of anti-rabies vaccination (Dzikwi et al., 2011). A large percentage of these dogs are free-roaming and usually left to scavenge for food. Dog ownership practice is very poor and most dogs are unvaccinated against vaccine-preventable diseases. Thus, rabies remains endemic in Nigeria among domestic dogs. A study in Thailand has shown that control of rabies is achievable following utilization of GIS in studying the epidemiology of the disease (Raunkaew, 2005). Similarly, GIS has been used to study and predict occurrence and distribution of schistosomosis in Local Government Areas of Ogun state, Nigeria. GIS delineates areas for intervention and assesses populations at risk so that resources can be optimized for the control of the disease (Ekpo et al., 2008).

The aim of this study was to determine and map the spatial distribution of rabies in Kaduna State (1999-2009) in order to plan an effective control programme for the disease. This aim was achieved by determining the spatial distribution of incidence of rabies from 1999-2009, track the pattern of movement of the disease and assess the efficiency of vaccine distribution in the state in order to plan a control strategy for rabies among the canine reservoirs in Kaduna state.

The spatial scope of the study was Kaduna state, Nigeria. The State is made up of 23 Local Government Areas and covers a total land mass of $4473.2 \mathrm{~km}^{2}$. It lies between latitude $9^{0} 01^{\prime \prime}$ to $11^{0} 34 " \mathrm{~N}$ and longitude $6^{0} 11^{\prime \prime}$ and $8^{0} 49^{\prime \prime}$.

\section{Materials and Methods}

Data on rabies was collected from the Ministry of Agriculture, Kaduna State. It comprises number of outbreaks, locations where cases were reported, species involved, and number of antirabies vaccines distributed by the Ministry of Agriculture throughout the state.

The data were reduced into tables and graphs. The Kaduna State map showing the Local Government Areas was downloaded from the internet (www.google.com). It was geo-referenced and outbreak locations by local governments were plotted using Arc GIS 9.2 software. Different colours are used to indicate the various years' outbreaks that were reported. Coloured lines representing different years are also used to hypothetically track movement of cases based on proximity from the location of the outbreaks in the previous year.

\section{Results and Discussion}

The 11 year record of rabies in Kaduna State indicates that there were 18 outbreaks of the disease reported annually except in the years 2001, 2003 and 2005. Each outbreak occurred in different localities. Nine Local Government Areas (LGAs) were involved as shown in Table 1, Figure 1 and Figure 2. A total of 32 cases of rabies were reported, five of which were confirmed by laboratory diagnosis. The others were diagnosed based on clinical signs. The annual modal case of two was reported in 2000, 2004 and 2006, while the highest number of annual cases was 14 reported in 2007.

Outbreaks were concentrated in the southern and eastern regions of the state. Lere LGA was a hot-spot for the disease outbreak in 2007 and 2009. About 27.27\% (9 incidences) of the cases reported occurred in Lere local government. In 2007, Kajuru LGA was also a hot spot while no case was reported throughout the 11 year period in some other LGAs. This was likely due to underreporting of the disease in the state and non-reporting in some LGAs. Rabies is on List "A" disease ranking in Nigeria and all outbreaks are required to be reported immediately they occur and stringently controlled (Federal Republic of Nigeria, 1982). Lack of data is a serious problem in the developing countries. Problems of availability of reliable and accurate data have plagued many health related studies such as cancer, malaria etc (Teppo, 1998). In areas where there is extreme hardship and economic setbacks for instance, surveillance for disease may not be a priority. Many African countries therefore are characterised by lack of systematic reporting and analysis of morbidity and mortality data (Iyun, 1995). In some parts of the world, rabies is either underreported or not even reported at all (Surdashan et al., 2007). This is highly unacceptable. If cases are not reported, the disease will continue to remain neglected and policy will not be made towards its control. 
To generate a useful data base for rabies in Kaduna State, all veterinary clinics must be mandated to report rabies cases to the relevant authorities for proper documentation and appropriate control actions in the long run.

The year 2007 had 14 cases (43.75\%) of all the reported cases during the study period. This may be as a result of increase in awareness about the disease. The first ever World Rabies Day was inaugurated on September 8, 2007 and thereafter marked on $28^{\text {th }}$ September annually (www.allianceforrabiescontrol.org). It is explainable that an increase in number of cases of a disease can be noticed where such factors as increased diagnostic ability, awareness, etc have increased in a given area.

Figure 3 shows the spread of the rabies from one local government to another among the reservoir domestic dog. The incidence started from Jema'a LGA in 1999, moved to Kagarko LGA and then Kachia LGA in 2000 from where it spread to Kaduna South LGA. By 2004, it had reached Zangon Kataf LGA to the South and Kajuru LGA to the North. Most likely, it proceeded in 2006 to Kaduna North LGA and South from Kajuru LGA while in 2007, it gained ground, spreading to Chikun LGA to the west, Kajuru, Kachia and Lere LGAs to the East. Cases of rabies were reported in 2008 in Chikun, Kajuru and in Kachia LGA. In 2009, Lere LGA recorded outbreaks possibly as a result of introduction from Kagarko LGAs. For the purpose of this study, tracking was made based on proximity, assuming the dogs migrated from one LGA to the nearest where an outbreak occurred in the subsequent year.

For rabies to be controlled in the dog population there is need for annual mass vaccination of the dog reservoir in endemic areas. From table 2, there was no vaccine distribution in the state for five years (2001-2003 and 2008-2009). Furthermore from the same table 2, a total of 14,232 rabies vaccine doses were distributed during the 11 year period in Kaduna state. The state has a population of about 6 million people (Federal Republic of Nigeria, 2007) and if the ratio of 1 dog to 10 humans is used (Bogel et al., 1982), then about 600,000 dogs are expected to be in the state. The WHO recommends vaccination of at least $70 \%$ of the dog population in an area to control the disease (WHO, 2005). This translates to about 420,000 doses required for distribution annually within the state, supposing that the number of dogs remain constant during the period. The actual doses distributed comes to an average of 1, 294 doses annually. This is just about $0.3 \%$ of the required doses. Voluntary vaccination of dogs is also very low and is not likely to contribute significantly. Vaccine distribution did not follow any logical pattern and seemed rather uncoordinated. From the data, though there was no rabies case reported in Zaria LGA during the study period, and vaccine doses were sent to this LGA.

To plan a control strategy for rabies among the canine reservoirs in Kaduna State, proper and coordinated vaccine distribution should begin with highly prioritized areas that are rabies hotspots, followed by areas that have reported outbreaks in order to control the disease before distribution to the "rabies free" LGAs. Rabies has almost 100\% case fatality rate, making it one of the world's most deadly diseases because there is no cure after clinical manifestation of the disease. In a study in Tanzania, only 33\% of dog bite victims were able to complete post exposure prophylaxis (PEP) following exposure to rabies because of the cost (Kaare, 2007). It is possible that the cost and access to PEP also hindered the bite victims from obtaining PEP. Another possible explanation is the low level of awareness about the disease and the appropriate actions for its prevention. In many localities, people resort to traditional practices for treating dog bite wounds. These are largely useless in preventing the disease, leading to clinical cases and unavoidable deaths.

\section{Conclusion}

Rabies cases could be said to be underreported in Kaduna State considering the fact that enlightenment and proper education of the people by the concerned authorities have not been adequately done. The distribution of rabies vaccines for dog was not planned and the vaccine doses distributed were too few to make any meaningful impact. Rabies control however is achievable but must be coordinated.

In view of the findings from the study, the following recommendations are therefore put forward:

1) Compulsory reporting of all rabies cases in all the LGAs and subsequently to the Ministry of Agriculture, Kaduna State should be embarked on through adequate enlightenment of the people.

2) Surveillance for rabies in all the LGAs must be carried out by the concerned authorities.

3) Sufficient doses of vaccines should be administered to ensure that not less than $70 \%$ of the dog population is vaccinated against rabies as required by the WHO.

4) Strategic execution of vaccination campaigns with more emphasis on the hot spot LGAs is very important.

5) Stock-piling of doses of human vaccines in the LGAs with emphasis on hotspots for dog rabies incase of human exposure. 


\section{Acknowledgements}

The assistance of Dr Dangiwa and cooperation of the Ministry of Agriculture, Kaduna State is appreciated. We also appreciate the technical assistance of Mr Robert Anger.

\section{References}

Bogel, K., Andral, L., Beran, G., Schneider, L.G., \& Wnadeler, A.A. (1982). Dog rabies elimination. A trend analysis and programme proposal prepared by a WHO working group. International Journal of Zoonoses, 9 , 97-112.

Boulger, L.K., \& Hardy, J. (1960). Rabies in Nigeria. West African Medical Journal, 9, 223-234.

Dzikwi, A.A., Umoh, J.U., Kwaga, J.K.P., \& Ahmad, A.A. (2011). Rabies vaccination and immune status of owned dogs in Zaria, Nigeria. Nigerian Veterinary Journal, 32, 204-207.

Ekpo, U.F., Mafiana, C.F., Adeofun, C.O., Solarin, A.R.T., \& Idowu, A.B. (2008). Geographic Information System and predictive maps of urinary Schistosomiasis in Ogun State, Nigeria. Biomedical Central, Infectious Diseases. [Online] Available: www.ncbi.nlm.nih.gov/pubmed/18513442.

Federal Republic of Nigeria. (1982). Guide to veterinary disease reporting in Nigeria. $2^{\text {nd }}$ edition, pp 33.

Federal Republic of Nigeria. (2007). Federal Republic of Nigeria Official Gazette, Federal Government Printer, Lagos, 9(24), 187.

Iyun, B.F. (1995). Cardiac morbidity in Nigerian society: Trends and Inter-relationships, In: Iyun, B.F., Verhasselt, Y \& Hellen, J.A. (eds). The Health of Nations, Brookefield: Avebury.

Kaare, M.T. (2007). Rabies control in Tanzania: Optimising the design and implementation of domestic dog mass vaccination programmes. An unpublished $\mathrm{PhD}$ Thesis, University of Edinburg. UK.

Kaduna State Ministry of Agriculture. (2010). Cases of Rabies in the state 1999-2009, A bulletin of the activities of the state ministry of Agriculture.

Oboegbulem, S.I. (1994): Rabies in man and animals. Fidelity Publishers, Enugu. 238pp.

Organizacion Panamericana de la Salud (OPS). (1983). Estragia plan de accion para le eliminacion de la rabia urbana en America Latina et final de la decada de 1980. Guayaquil. Ecuador.

Perry, B.D. (1993). Dog ecology in eastern and Southern Africa and implications for rabies control. Ondersterpoort Journal of Veterinary Research, 60, 429-436.

Radostits, O.N., Blood, D.C., \& Gay, C.C. (1995). Veterinary medicine. $8^{\text {th }}$ ed. ELBS Bailliere Tindall, London, 1087-1094.

Raunkaew, N. (2005). GIS and epidemiology. Journal of Medical Association of Thailand, 88, 1735-1738.

Rupprecht, C.E., Smith, J.S., Fekadu, M., \& Childs, J.E. (1995). The ascension of wildlife rabies: A cause for public health concern or intervention? Emerging Infectious Diseases, 1, 107-114. http://dx.doi.org/10.3201/eid0104.950401

Rupprecht, C.E., Willoughby, R., \& Slate, D. (2006). Current and future trends in the prevention, treatment and control of rabies. Expert Review of Anti-infective Therapy, 4, 1021-1038. http://dx.doi.org/10.1586/14787210.4.6.1021

Sudarshan, M.K., Madhusudana, S.N., Mahendra, B.J., Rao, N.S.N., Ashwath Narayana, D.H., Adbul Rahman, S., Meslin, F-X., Lobo, D., Rravikumar, K., \& Gangaboraiah, K. (2007). Assessing the burden of human rabies in India: a result of a national epidemiological survey. International Journal of Infectious Diseases, 11, 29-35. http://dx.doi.org/10.1016/j.ijid.2005.10.007

Taiwo, V.O., Antia, R.E., Adeniran, G.A., Alaka, O.O., \& Ohore, O.G. (1998). Rabies in dogs and cats in Southwestern Nigeria.: Laboratory reports. Tropical Veterinarian, 16, 9-13.

Teppo, L. (1998). Problems and possibilities in the use of cancer data by GIS-Experience in Finland, Gatrell, A.C., \& Loytonen, M. (eds). GIS and Health, Taylor and Francis, Philadelphia, 167-177

W.H.O. (1994). World survey of rabies for the year 1992. Geneva, Switzerland.

W.H.O. (2005). WHO Expert Consultation on Rabies. WHO Technical Report series. 931. www.allianceforrabiescontrol.org 
Table 1. Incidences of rabies in Kaduna State by Local Governments Areas from 1999 to 2009

\begin{tabular}{ccc}
\hline Local Government Area & Reported Incidence & Year \\
\hline Jemma & 1 & 1999 \\
Kagarko & 1 & 2000 \\
Kachia & 1 & 2000 \\
Kachia & 1 & 2002 \\
Kaduna South & 3 & 2002 \\
Kajuru & 1 & 2004 \\
Zangon Kataf & 1 & 2004 \\
Kaduna South & 1 & 2006 \\
Kaduna North & 1 & 2006 \\
Kachia & 1 & 2007 \\
Chikun & 2 & 2007 \\
Lere & 6 & 2007 \\
Kajuru & 5 & 2007 \\
Kachia & 1 & 2008 \\
Chikun & 1 & 2008 \\
Kajuru & 2 & 2008 \\
Lere & 3 & 2009 \\
Total & 32 & \\
\hline
\end{tabular}

Source: Ministry of Agriculture, Kaduna State (2010) 
Table 2. Anti-rabies vaccine distribution from 1999 to 2009 in Kaduna State by LGAs

\begin{tabular}{|c|c|c|}
\hline Year & LGA & Doses issued \\
\hline \multirow[t]{3}{*}{1999} & Kagarko & 10 \\
\hline & Kaduna North and South & 97 \\
\hline & Zaria & 16 \\
\hline Total & & 123 \\
\hline \multirow{3}{*}{2000} & Kaduna North and South & 280 \\
\hline & Kagarko & 50 \\
\hline & Kajuru & 100 \\
\hline Total & & 430 \\
\hline 2001 & - & - \\
\hline 2002 & - & - \\
\hline 2003 & - & - \\
\hline \multirow[t]{4}{*}{2004} & Zaria & 1400 \\
\hline & Jema'a & 1400 \\
\hline & Saminaka & 760 \\
\hline & Kaduna North and South & 1403 \\
\hline Total & & 4963 \\
\hline \multirow[t]{8}{*}{2005} & Kaduna North and South & 1327 \\
\hline & Jema'a & 1650 \\
\hline & Chikun & 25 \\
\hline & Saminaka & 270 \\
\hline & Kagarko & 100 \\
\hline & Kachia & 1000 \\
\hline & Kajuru & 65 \\
\hline & Zaria & 210 \\
\hline Total & & 4647 \\
\hline \multirow[t]{5}{*}{2006} & Kaduna North and South & 15 \\
\hline & Jema'a & 10 \\
\hline & Zaria & 5 \\
\hline & Chikun & 4 \\
\hline & Kagarko & 80 \\
\hline Total & & 114 \\
\hline \multirow[t]{5}{*}{2007} & Kaduna North and South & 2425 \\
\hline & Zaria & 505 \\
\hline & Jema'a & 500 \\
\hline & Saminaka & 500 \\
\hline & Kachia & 25 \\
\hline Total & & 3955 \\
\hline 2008 & - & - \\
\hline 2009 & - & - \\
\hline Total & & 14,232 \\
\hline
\end{tabular}

Source: Ministry of Agriculture, Kaduna state (2010) 


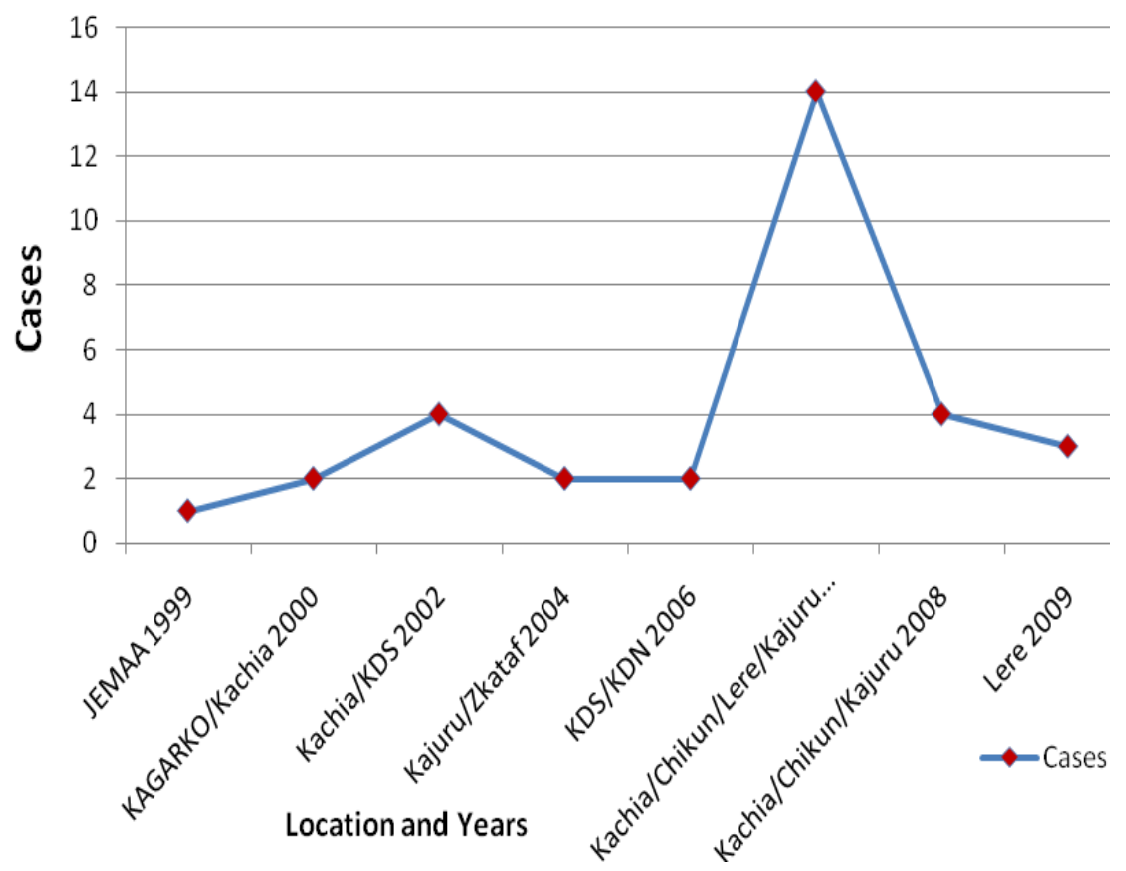

Figure 1. Graphical representation of incidences of rabies in Kaduna state by local governments (1999-2009)

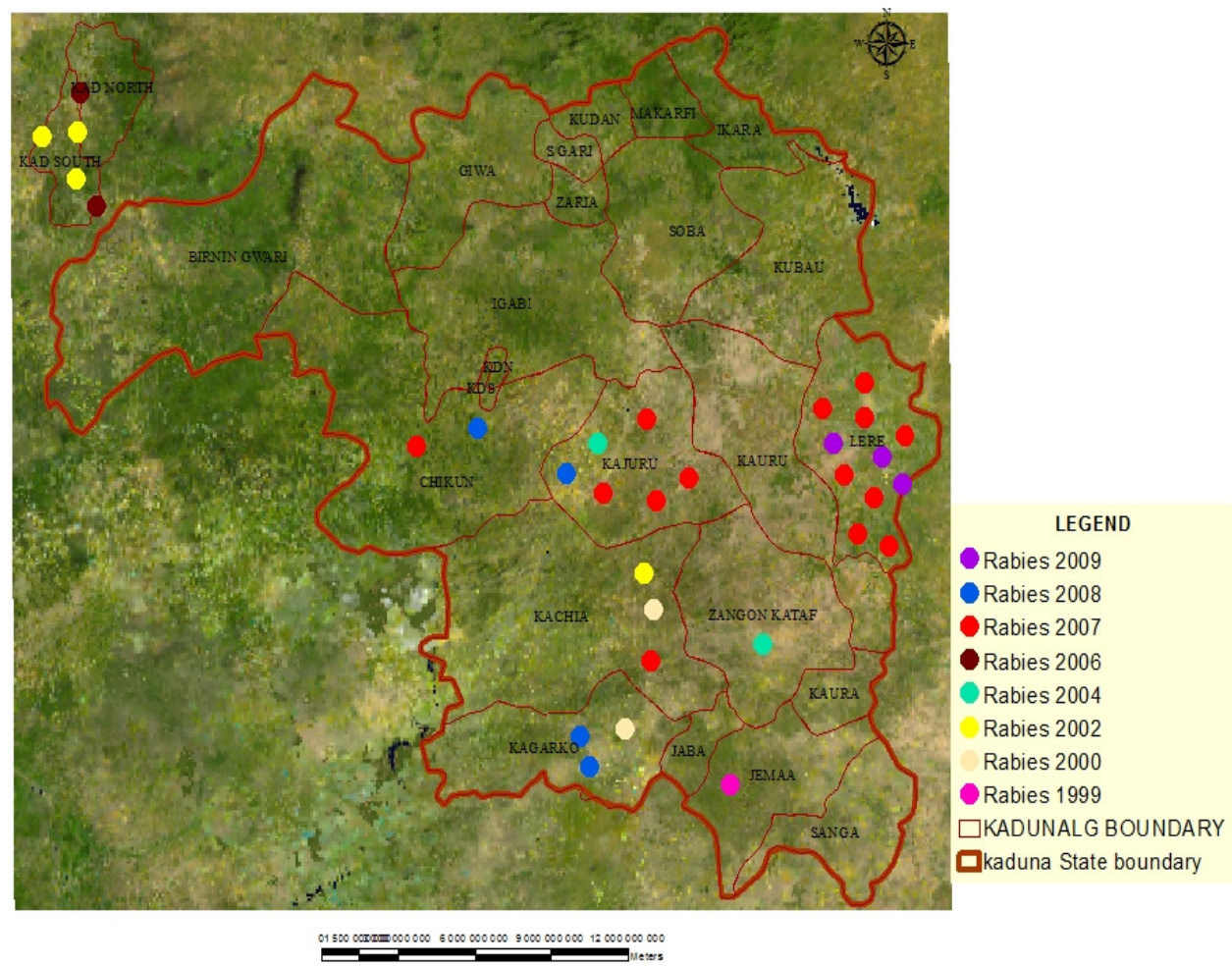

Figure 2. The spatial distribution of incidence of rabies in Kaduna state by local governments (1999-2009) Source: GIS analysis, 2011 


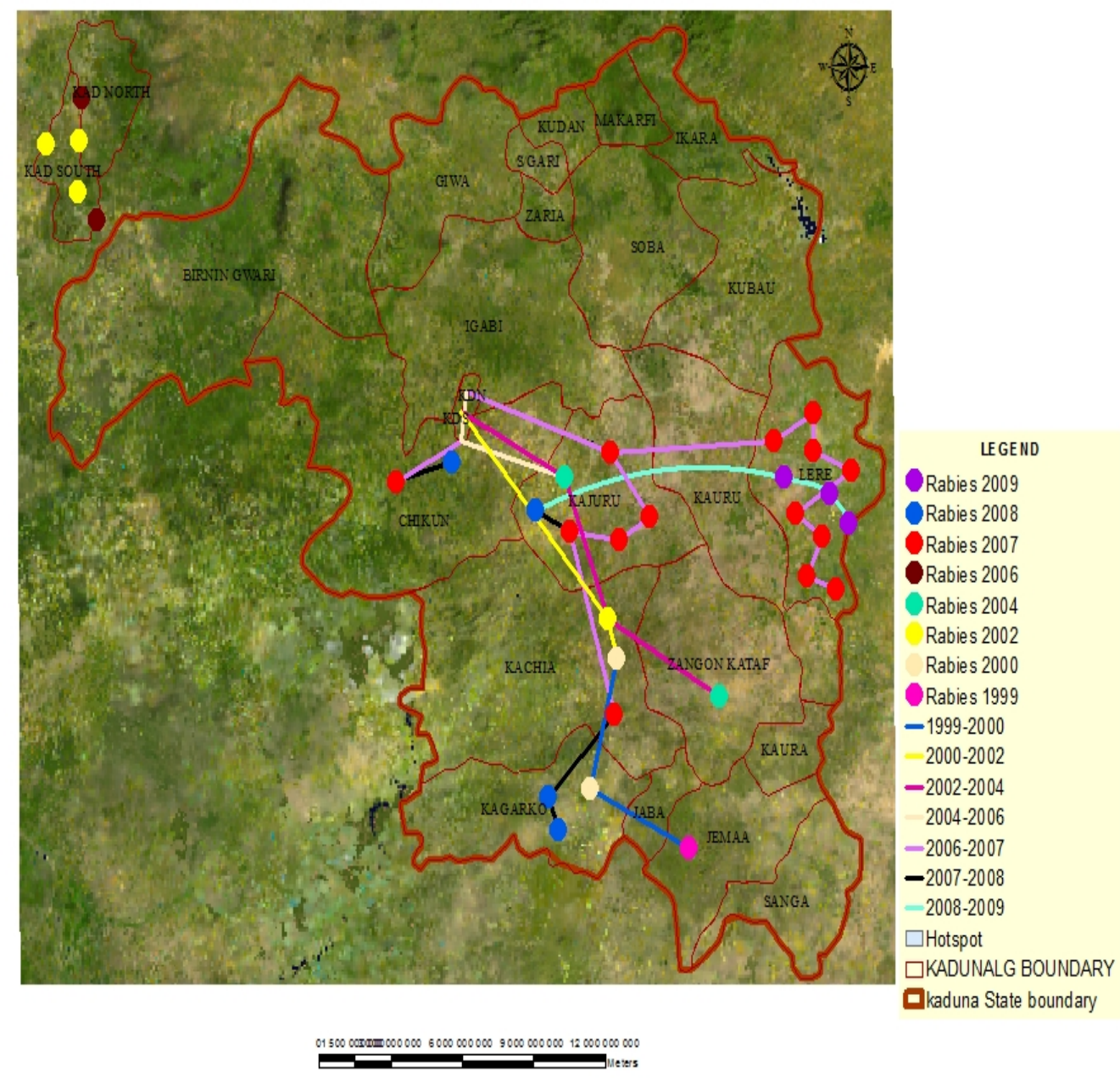

Figure 3. The spread of rabies incidence in Kaduna state (1999-2009)

Source: GIS Analysis, 2011 